\title{
Promising bulk nanostructured Cu2Se thermoelectrics via high throughput and rapid chemical synthesis
}

Tafti, Mohsen Y.; Ballikaya, Sedat; Khachatourian, Adrine Malek ; Noroozi, Mohammad ; Saleemi, Mohsin; Han, Li; Van Nong, Ngo; Bailey, Trevor; Uher, Ctirad ; Toprak, Muhammet S.

\author{
Published in: \\ RSC Advances \\ Link to article, DOI: \\ 10.1039/C6RA23005A \\ Publication date: \\ 2016 \\ Document Version \\ Peer reviewed version \\ Link back to DTU Orbit
}

Citation (APA):

Tafti, M. Y., Ballikaya, S., Khachatourian, A. M., Noroozi, M., Saleemi, M., Han, L., Van Nong, N., Bailey, T., Uher, C., \& Toprak, M. S. (2016). Promising bulk nanostructured Cu Se thermoelectrics via high throughput and rapid chemical synthesis. RSC Advances, 6(112), 111457-111464. Ittps://doi.org/10.1039/C6RA23005A

\section{General rights}

Copyright and moral rights for the publications made accessible in the public portal are retained by the authors and/or other copyright owners and it is a condition of accessing publications that users recognise and abide by the legal requirements associated with these rights.

- Users may download and print one copy of any publication from the public portal for the purpose of private study or research.

- You may not further distribute the material or use it for any profit-making activity or commercial gain

- You may freely distribute the URL identifying the publication in the public portal 


\title{
High ZT achieved in nanostructured $\mathrm{Cu}_{2} \mathrm{Se}$ fabricated by Microwave Assisted Organometallic Synthesis
}

\author{
Mohsen Y. Tafti ${ }^{a,}$, Sedat Ballikaya ${ }^{b, c}$, Adrine Malek Khachatourian ${ }^{a}$, Mohammad Noroozi $^{a}$, \\ Mohsin Saleemi ${ }^{a, d}$, Li Han $^{e}$, Ngo V. Nong ${ }^{e}$,Trevor Bailey ${ }^{c}$, Ctirad Uher ${ }^{c}$, Muhammet S. Toprak ${ }^{a, *}$ \\ ${ }^{a}$ Department of Materials \& Nano-Physics, KTH Royal Institute of Technology, Stockholm, \\ Sweden \\ ${ }^{\mathrm{b}}$ Department of Physics, Istanbul University, Istanbul, Turkey \\ ${ }^{c}$ Department of Physics, University of Michigan, Ann Arbor, MI, 48109, USA \\ ${ }^{\mathrm{d}}$ Department of Material and Environmental Chemistry, Stockholm University, Stockholm, \\ Sweden \\ ${ }^{\mathrm{e}}$ Department of Energy Conversion and Storage, Technical University of Denmark, Roskilde, \\ Denmark \\ *Email: toprak@kth.se, Tel: +46-8-7908344 \\ mohsenyt@kth.se, Tel: +46703199831 \\ Present Address \\ KTH Royal Institute of Technology \\ Functional Materials Division \\ Department of Materials \& Nano-Physics \\ School of Information and Communication Technology \\ Isafjordsgatan 22, SE-164 40 Kista Stockholm, Sweden
}

KEYWORDS: Thermoelectric, Microwave Assisted Synthesis, Copper Selenide, Nanoengineering.

\section{ABSTRACT}

In this article we report a facile, highly energy-efficient synthesis route for the fabrication of nanostructured bulk thermoelectric copper selenide $\left(\mathrm{Cu}_{2} \mathrm{Se}\right)$. Using microwave-assisted thermolysis, nanopowders of $\mathrm{Cu}_{2} \mathrm{Se}$ were produced starting from commonly available precursor 
materials. Optimized compaction parameters were achieved through an investigation of different factors in the compaction process to achieve enhanced thermoelectric properties. The high $Z T$ value of 2 obtained at $900 \mathrm{~K}$ for optimized SPS-compacted $\mathrm{Cu}_{2} \mathrm{Se}$ nanopowders exceeds the state of the art $\mathrm{Cu}_{2} \mathrm{Se}$ by $25 \%$ at the same temperature. The results demonstrate the prominent improvement in $Z T$ attributed both to the low thermal conductivity, as low as $0.38 \mathrm{~W} / \mathrm{m}-\mathrm{K}$ at 900 $\mathrm{K}$, and the enhancement in the power factor of nanostructured $\mathrm{Cu}_{2} \mathrm{Se}$.

\section{Introduction}

Thermoelectric (TE) materials are solid-state energy-converters, which can convert heat into electricity or serve as Peltier heat pumps. They have a wide range of applications in thermal management and power generation ${ }^{[1]}$. The materials are classified with respect to their intended operational range as low (room temperature up to $250{ }^{\circ} \mathrm{C}$ ), medium (from $200{ }^{\circ} \mathrm{C}$ up to $600{ }^{\circ} \mathrm{C}$ ) and high temperature (above $600{ }^{\circ} \mathrm{C}$ ) ${ }^{[1]}$ TEs. Several families of materials have been introduced for each respective temperature range. Recently, copper selenide $\left(\mathrm{Cu}_{2-\mathrm{x}} \mathrm{Se}\right)$ has gained a renewed interest for the medium temperature range operation. Copper selenide structures have previously been used in photovoltaic cells and devices ${ }^{[2,3]}$ and are being considered even in biological systems ${ }^{[4]}$. This renewed interest can be attributed to the low thermal conductivity of the material as well as to its phase changing nature, which is an interesting aspect of the material ${ }^{[5-7,}$ ${ }^{8-10]}$. The constituent elements are abundant in nature, and are considered as more benign in comparison to many other $\mathrm{TE}$ structures, especially those containing $\mathrm{Pb}, \mathrm{Sb}$, $\mathrm{As}$, etc. Additionally, $\mathrm{Cu}_{2-\mathrm{x}} \mathrm{Se}$ exhibits an electronic-ionic conduction mechanism that has a great influence on different properties, such as the specific heat capacity $\left(c_{p}\right)$, which approaches the theoretical limit of solid crystalline materials compared to liquids ${ }^{[5,6,8,11,12]}$. Different methods

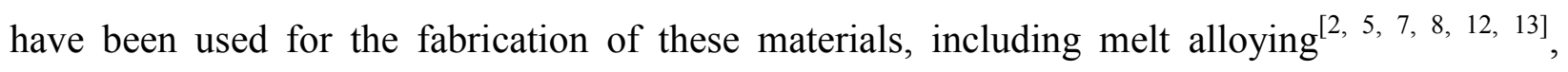


mechanical alloying (ball milling) ${ }^{[6,14,15]}$, self-propagating high-temperature synthesis (SHS) ${ }^{[10]}$, and chemical routes using aqueous solutions either directly ${ }^{[9,16,17]}$ or solvothermally precipitated using autoclave $\mathrm{e}^{[18]}$ or organometallic precursors ${ }^{[4,19]}$. Some of these processes require high temperatures (above $1000 \mathrm{~K}$ ), long processing times, which consumes a lot of energy, or inert atmosphere glove boxes for powder handling, which are expensive.

Our motivation for this study is to develop an alternative, fast, energy and resource effective synthesis method for $\mathrm{Cu}_{2-\mathrm{x}} \mathrm{Se}$-based compounds with improved performance intended for TE applications. Our technique is based on as-received materials and the synthesis is performed via microwave (MW) assisted heating at temperatures much lower than those used in conventional methods $\left(250^{\circ} \mathrm{C}\right)$. Fabricated nanomaterials have been carefully consolidated to preserve the nanostructure and characterized for their temperature-dependent TE properties depending on the sintering temperature and pressure.

\section{Experimental}

Copper acetate $\left[\mathrm{Cu}\left(\mathrm{CO}_{2} \mathrm{CH}_{3}\right)_{2} \cdot \mathrm{H}_{2} \mathrm{O}\right]$, selenium powder $(\mathrm{Se},>99.5 \%)$, and the organic solvents oleic acid $\left(\mathrm{C}_{18} \mathrm{H}_{34} \mathrm{O}_{2}\right)$, 1-Octadecene $\left(\mathrm{C}_{18} \mathrm{H}_{36}, \mathrm{ODE}\right)$, and Trioctylphosphine $\left[\mathrm{P}\left(\mathrm{C}_{8} \mathrm{H}_{17}\right)_{3}, \mathrm{TOP}\right]$ methanol and hexane $\left(\mathrm{C}_{6} \mathrm{H}_{14}\right)$ were all purchased from Sigma Aldrich and used as received. The precursor mixture was prepared by adding a stoichiometric amount of copper acetate and Se powder in a MW glass vial with $4 \mathrm{ml}$ of ODE and $8 \mathrm{ml}$ of oleic acid. The vial was then sealed with silicon septa caps and degassed with several purges of nitrogen followed by vacuum, into which $2 \mathrm{ml}$ of TOP was added. The degassing process is performed to prevent TOP oxidation. The vial was then loaded into the laboratory MW synthesizer (Biotage ${ }^{\circledR}$ Initiator+), pre-stirred for 2 minutes and then heated with the following parameters; a MW power of $400 \mathrm{~W}$, a synthesis temperature of $250{ }^{\circ} \mathrm{C}$, and a synthesis holding time of $5 \mathrm{~min}$. The greenish color suspension 
turned into brownish color after the synthesis. The powders were then washed several times with hexane and methanol and left in vacuum oven to dry at $60{ }^{\circ} \mathrm{C}$ for 3 hours. The dried powders then underwent several characterization processes, including Scanning Electron Microscopy (SEM, Zeiss Ultra 55), Transmission Electron Microscopy (TEM, Jeol JEM 2100), and X-ray Powder Diffraction (XRPD) (PANalytical Empyrean, PANalytica X'pert PRO with Anton Paar XRK 900 High Temperature Chamber). Afterwards, the powders were compacted using Spark Plasma Sintering (SPS, Dr. Sinter 825). The optimized sintering parameters were identified as a heating rate of $75^{\circ} \mathrm{C} / \mathrm{min}$, maximum temperature of $400{ }^{\circ} \mathrm{C}$, and no holding time. The cooling of the pellets had to be controlled to minimize the effect of the phase transition on the structural integrity of the pellet. All high temperature transport measurements were carried out under Ar atmosphere in the range of $300-900 \mathrm{~K}$. The Seebeck coefficient (S) and the electrical conductivity measurements were performed using a ZEM 3 (Ulvac Technologies) system. The total thermal conductivity $\kappa$ was calculated using the equation $\kappa=D \cdot \rho \cdot C_{p}$, where $D$ is the thermal diffusivity, $\mathbf{c}_{\mathrm{p}}$ the specific heat capacity and $\rho$ the bulk density of the pellet. The thermal diffusivity was measured using a laser flash analysis system (LFA 457, Netzsch). The specific heat capacity, $c_{p}$, was measured by Differential Scanning Calorimetry (Netzsch-DSC 404 Pegasus214 Polyma), and the density was obtained from the Archimedes method. High temperature Seebeck coefficient and electrical conductivity measurements were repeated at the University of Michigan to confirm the electronic transport properties of these compounds.

\section{Results and Discussion}

By a careful exploration of the MW synthesis parameters, the optimum synthesis temperature was identified as $250{ }^{\circ} \mathrm{C}$ and the holding time of $5 \mathrm{~min}$. The reaction process on the MW synthesizer is mechanized using a sample loader therefore the human influence is minimized. 
This results in highly reproducible results. Due to the limitation of the volume on the particular instrument a full batch results in about 12 grams of nanopowders. In this work several batches underwent the same procedure and the XRD results were identical. Therefore the study performed on the compaction and optimization of the compaction parameters were performed on the same big batch of nanopowders. Figure 1a illustrates the XRPD pattern for samples at different stages of processing: as-prepared, SPS-compacted, and after measurements of the TE transport properties.
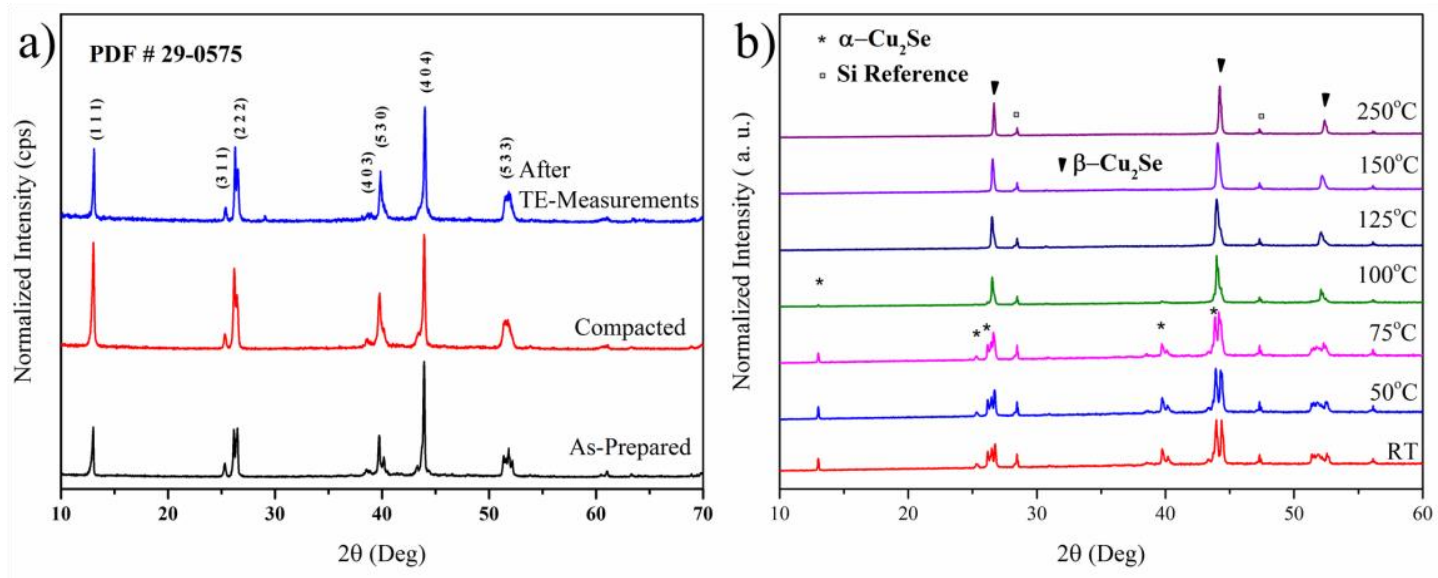

Figure 1: Room temperature XRPD pattern of a) powders at different processing steps; asprepared, compacted powder and the pellet after the TE measurements and b) temperaturedependent XRPD of the copper selenide powder (indexed with ICDD Card number 29-0575 for $\alpha-\mathrm{Cu}_{2} \mathrm{Se}(*), 01-079-1841$ for $\beta-\mathrm{Cu}_{2} \mathrm{Se}(\boldsymbol{\nabla})$ and and $98-002-9287$ for $\left.\mathrm{Si}(\square)\right)$

Depending on the temperature, $\mathrm{Cu}_{2-\mathrm{x}} \mathrm{Se}$ has two main phases: a monoclinic $\alpha$ phase below 140 ${ }^{\circ} \mathrm{C}$ and a cubic $\beta$ phase above $140{ }^{\circ} \mathrm{C}$. The XRPD $2 \theta$ scans of the compacted sample show a slight shift with respect to the as-prepared sample from higher angles to lower angles at 26 and 39.7 degrees, corresponding to the $\left(\begin{array}{lll}2 & 2 & 2\end{array}\right)$ and $\left(\begin{array}{lll}5 & 3 & 0\end{array}\right)$ planes, respectively, which can be attributed to the recrystallization of some of the defects and/ or amorphous parts and the formation of the proper phase. Additionally, the room temperature XRPD pattern taken after TE 
transport measurements shows the transformation of most of the $\mathrm{Cu}_{2-\mathrm{x}} \mathrm{Se}$ from the $\beta$ phase to the $\alpha$ phase. Moreover, Figure $1 \mathrm{~b}$ illustrates the temperature-dependent XRPD of the powder (a mixture of the as-prepared $\mathrm{Cu}_{2-x} \mathrm{Se}$ nanopowder and $\mathrm{Si}$ powder used as the internal reference) at elevated temperatures and confirms the $\alpha$ to $\beta$ phase transition around $100{ }^{\circ} \mathrm{C}$, a much lower temperature than that reported in the literature. According to Chakrabarti et al. ${ }^{[20]}$ and Gahtori et al. ${ }^{[15]}$, the transformation takes place at above $120{ }^{\circ} \mathrm{C}$. In the material under investigation, the phase transformation commences at temperatures lower than $100{ }^{\circ} \mathrm{C}$ and is completed at about $110{ }^{\circ} \mathrm{C}$. This transformation is also confirmed by the DSC measurements, which were performed in 2 cycles, as displayed in Figure 2. The data reveal that the phase transformation process is reversible, the traces being identical upon heating and cooling. The process parameter was set for $2{ }^{\circ} \mathrm{C} / \mathrm{min}$ increments, and the phase transition takes place at about $105{ }^{\circ} \mathrm{C}$, where we observe a sharp peak in the derivative of the heat flow.

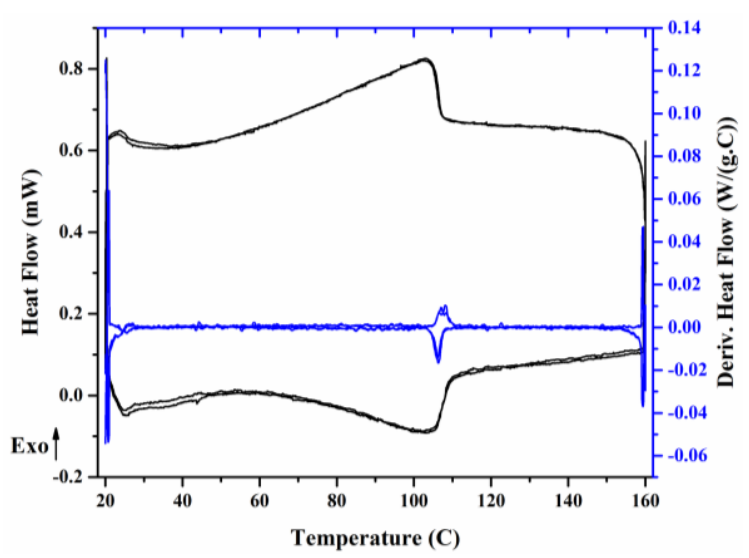

Figure 2: DSC thermogram of $\mathrm{Cu}_{2-\mathrm{x}} \mathrm{Se}$ nanopowder with 2 heating-cooling cycles.

Figure 3 displays SEM micrographs of the as-prepared powder. The particle size ranges from $50 \mathrm{~nm}$ up to several hundreds of nanometers, with an average size of $150 \mathrm{~nm} \pm 20 \mathrm{~nm}$ (counting about 300 particles/grain from several micrographs). Additionally, secondary particles consisting of much smaller domains, as primary particles, are visible in Figure $3 \mathrm{~b}$. These primary particles 
have sizes in the range of $15-40 \mathrm{~nm}$, with an average size of $25 \pm 5 \mathrm{~nm}$. This is seen from the TEM image presented in the inset of Figure 3Error! Reference source not found.b, which confirms the presence of the primary smaller particles within the observed clusters.

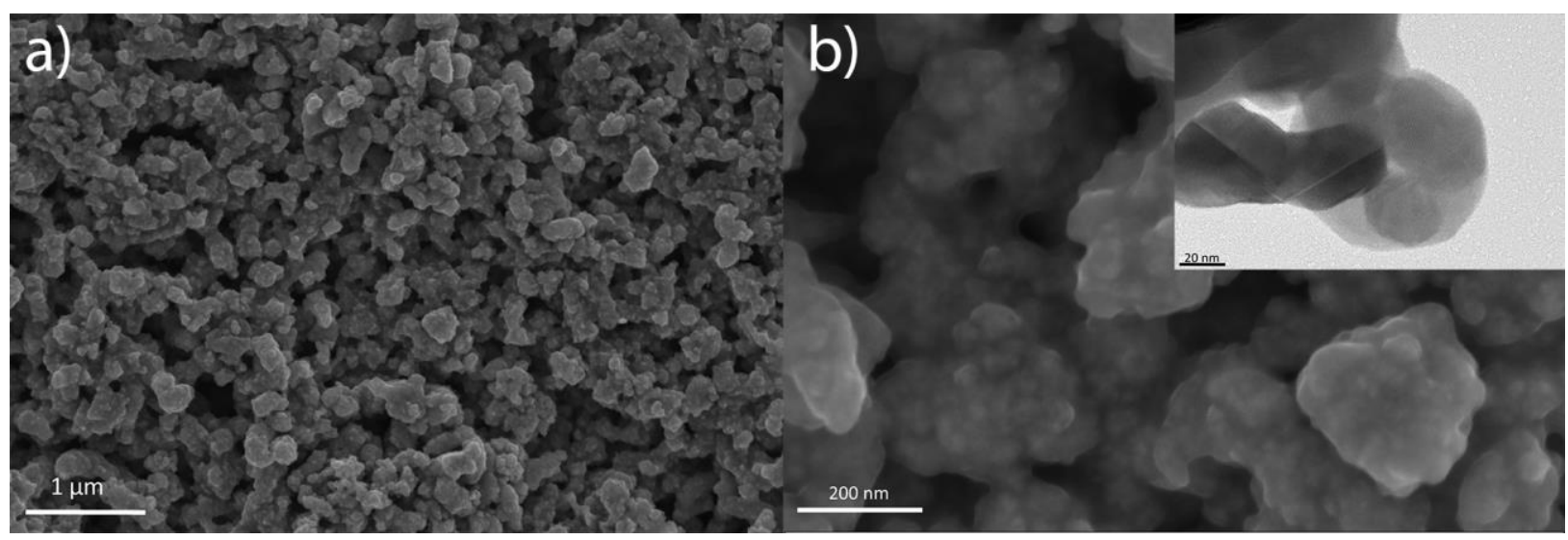

Figure 3: a), b) SEM micrographs of the as-prepared $\mathrm{Cu}_{2-\mathrm{x}} \mathrm{Se}$ nanopowder at different magnifications (inset in (b) is the TEM micrograph of as-prepared $\mathrm{Cu}_{2-\mathrm{x}} \mathrm{Se}$ nanopowder).

HRTEM was performed on the as-prepared powder samples to more closely observe the crystal structure and geometry of the primary particles in the cluster. Figure 4 represents the TEM micrograph of the as-prepared powder at different magnifications. The HRTEM image depicts the primary particles with a high crystallinity. The interplanar distance was calculated as $0.33 \mathrm{~nm}$, corresponding to the (2 2 2) plane of the $\alpha-\mathrm{Cu}_{2-\mathrm{x}} \mathrm{Se}$ phase matched with the ICDD card number 29-0575. The FFT performed on the designated area also displays the periodicity of the interplanar distance. 


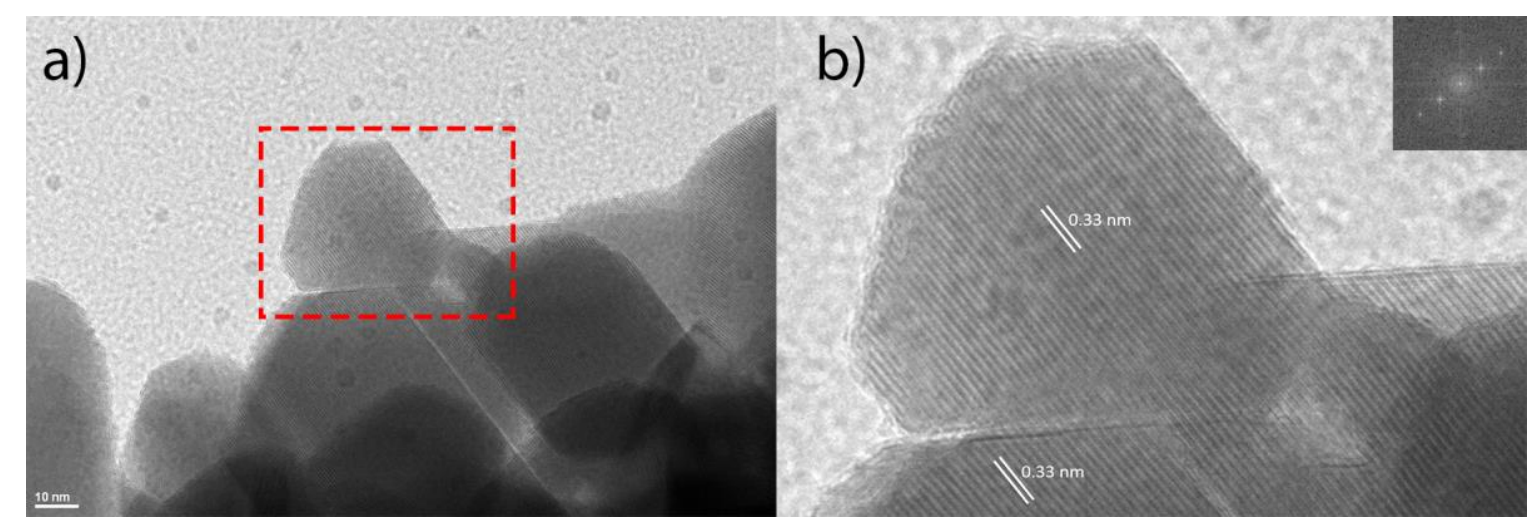

Figure 4: a) Low, and b) high resolution TEM micrographs of as-prepared powder with the corresponding FFT of the interplanar distances.

Table 1 lists the SPS processing conditions for the samples used for transport characterization. The heating rate during the SPS process was selected in such a way as to prevent any accidental surge of current that could have melted the powder. Additionally, the densification curve provided us with the plateau limit for the compaction (data not shown). The optimum parameters were identified as a $400{ }^{\circ} \mathrm{C}$ compaction temperature with a heating rate of $75{ }^{\circ} \mathrm{C} / \mathrm{min}$ and no holding time. The most important difference in the SPS process parameters was the fact that in one compaction processes, the load/pressure on the sample was released during cooling $\left(\mathrm{Cu}_{2} \mathrm{Se} \_\right.$Nano_nl $)$, while in the other process, the load/pressure was maintained $\left(\mathrm{Cu}_{2} \mathrm{Se} \_\right.$Nano_1).

Table 1. SPS processing conditions and the resulting sample density.

\begin{tabular}{|c|c|c|c|c|c|c|}
\hline Sample Tag & $\begin{array}{c}\text { Chemical process } \\
\text { parameters }\end{array}$ & $\begin{array}{l}\text { Mass density } \\
\left(\mathrm{g} / \mathrm{cm}^{3}\right)\end{array}$ & $\begin{array}{l}\text { Heating rate } \\
\left({ }^{\circ} \mathrm{C} / \mathrm{min}\right)\end{array}$ & $\begin{array}{c}\text { Compaction } \\
\text { temperature }\left({ }^{\circ} \mathrm{C}\right)\end{array}$ & $\begin{array}{l}\text { Holding } \\
\text { Time }\end{array}$ & Cooling load \\
\hline $\mathrm{Cu}_{2} \mathrm{Se} \_\mathrm{Nano} \_n l$ & $\begin{array}{l}250^{\circ} \mathrm{C} 5 \mathrm{mins} \\
\text { holding time }\end{array}$ & $5.97(\approx 90 \%)$ & 75 & 400 & 0 & No \\
\hline $\mathrm{Cu}_{2} \mathrm{Se} \_$Nano_1 & $\begin{array}{l}250^{\circ} \mathrm{C} 5 \text { mins } \\
\text { holding time }\end{array}$ & $6.02(\approx 90 \%)$ & 75 & 400 & 0 & Yes \\
\hline
\end{tabular}

The density of the compacted $\mathrm{Cu}_{2} \mathrm{Se}$ nanopowder samples was around $90 \%$ of the theoretical density, a relatively smaller density compared to the density of nano structured and bulk $\mathrm{Cu}_{2} \mathrm{Se}$ reported by other groups ${ }^{[8,16,21]}$. This might be due to differences in the grain size ${ }^{[22]}$. Different 
particle sizes have different surface energy, which may cause resistance to further compaction ${ }^{[23]}$. SEM micrographs of two compacted samples with different compaction parameters are presented in Figure 5a and $b$. Although both samples have nearly the same density, the sample $\mathrm{Cu}_{2} \mathrm{Se} \_$Nano_nl contains a mixture of nano- and micron-sized grains, while in the other sample the grains have grown quite a lot, a feature attributed to maintaining the load/pressure even during the cooling step. Due to the high pressure and sintering temperature, as well as the very short exposure time to the sintering temperature, several smaller particles might start diffusing into each other and aggregate to form larger grains, while some other particles remain small. During the cooling stage that maintained the load/pressure on the compacted powder, the diffusion of small particles might be enhanced; thus, the sample labeled as nano $\mathrm{Cu}_{2} \mathrm{Se}_{-} 1$ has much larger grain size in comparison to the sample designated as $\mathrm{Cu}_{2} \mathrm{Se}$ nnl. Nano and micro grain sizes and their distribution in the structure have a strong influence on the TE properties of the compound.

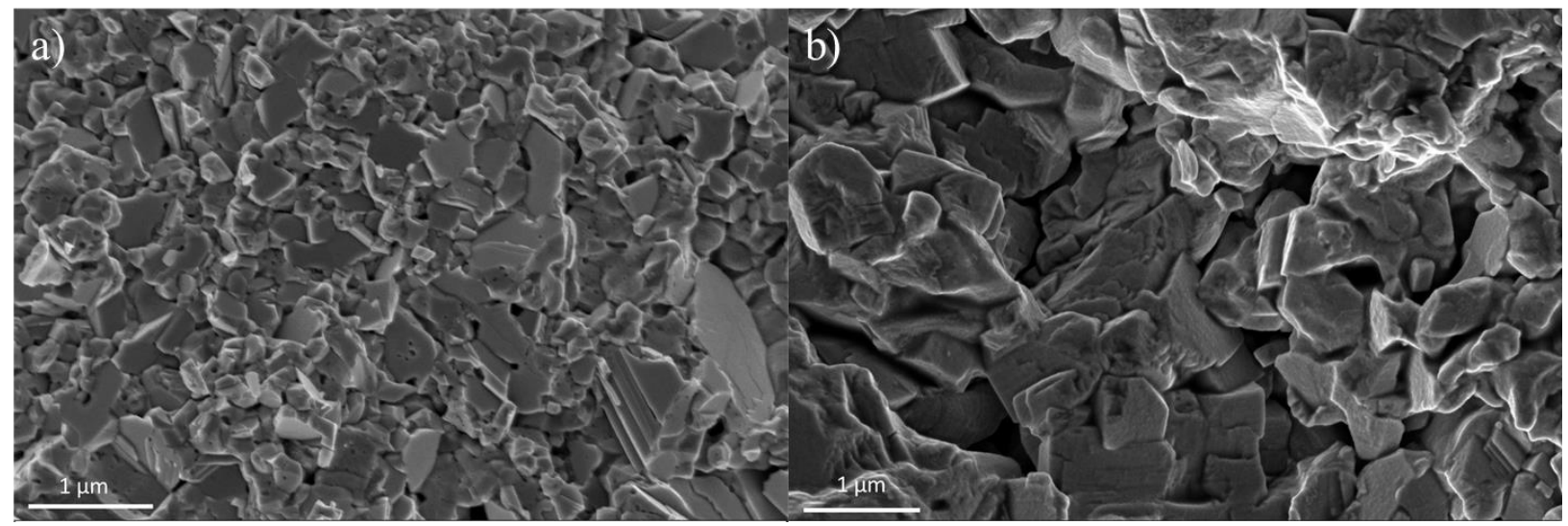

Figure 5: SEM micrographs of a) $\mathrm{Cu}_{2} \mathrm{Se}_{-} \mathrm{Nano} \_n l$ and b) $\mathrm{Cu}_{2} \mathrm{Se}_{-} \mathrm{Nano} \_1$ at similar magnifications.

TE transport properties of nanostructured $\mathrm{Cu}_{2} \mathrm{Se}$ samples were determined based on measurements of the Seebeck coefficient, electrical conductivity, and thermal conductivity 
between 300 and $900 \mathrm{~K}$. The results are illustrated in Figure 6. The electrical conductivity (Figure 6a) decreases with the increasing temperature for all samples, likely due to electrons being scattered by acoustic phonons, which is a typical behavior of heavily doped semiconductor materials. The sample with no load applied during cooling shows a higher electrical conductivity of $1126 \mathrm{~S} / \mathrm{cm}$ compared to the conductivity of $884 \mathrm{~S} / \mathrm{cm}$ measured on the sample on which the load was maintained during the cooldown. Both of the samples show a sudden drop in the electrical conductivity at the phase transition temperature, followed by an increase and the final values of $170 \mathrm{~S} / \mathrm{cm}$ for $\mathrm{Cu}_{2} \mathrm{Se} \_$Nano_nl and about $100 \mathrm{~S} / \mathrm{cm}$ for $\mathrm{Cu}_{2} \mathrm{Se}_{-}$Nano_1 reached at 900 K. Comparing the electrical conductivity with the values reported by Gahtori et al. ${ }^{[15]}$ and Yu et al. ${ }^{[6]}$, some $15 \%(\approx 1000 \mathrm{~S} / \mathrm{cm})$ and almost $75 \%(\approx 725 \mathrm{~S} / \mathrm{cm})$ enhancements are observed at RT, respectively. This might be due to the percolated network of large (micron-sized) grains in the $\mathrm{Cu}_{2} \mathrm{Se} \_n l$ compound. The conductivity values follow the same trend in all 3 samples and fall to a value of $150 \mathrm{~S} / \mathrm{cm}$ at $900 \mathrm{~K}$ in $\mathrm{Cu}_{2} \mathrm{Se} \_$Nano_nl, similar to the work of Gahtori et al. ${ }^{[15]}$ and about $50 \%$ higher than the value $(\approx 95 \mathrm{~S} / \mathrm{cm})$ reported by Yu et al. ${ }^{[6]}$.

The positive sign of the Seebeck coefficient confirms that holes are the main carriers in both samples (Figure 6b). The RT Seebeck coefficient value is $70 \mu \mathrm{V} / \mathrm{K}$ and increases to about 250 $\mu \mathrm{V} / \mathrm{K}$, which is roughly $25 \%$ more than values reported in the work of Gahtori et al. ${ }^{[15]} \approx 200$ $\mu \mathrm{V} / \mathrm{K})$, but roughly similar to the values reported by $\mathrm{Yu}$ et al. ${ }^{[6]}(\approx 255 \mu \mathrm{V} / \mathrm{K})$. The temperature dependence of the Seebeck coefficient indicates that there is a tendency for an extrinsic to intrinsic transition at high temperatures. Using the empirical relation for the band gap, $E_{g}=2 e S_{\max } T_{\max }$, and our Seebeck coefficient data ${ }^{[24]}$, the band gap energy is estimated to be 0.72 $\mathrm{eV}$ for the sample $\mathrm{Cu}_{2} \mathrm{Se} \_\mathrm{Nano} \_n l$, and $0.83 \mathrm{eV}$ for the sample $\mathrm{Cu}_{2} \mathrm{Se} \_$Nano_l. Both values are relatively lower than the band gap energy of nano- $\mathrm{Cu}_{2} \mathrm{Se}$ reported by Riha et al. ${ }^{[25]}$. The wide 
range in observed band gap energies and different electronic behaviors in our samples compared to the literature might be due to differences in the $\mathrm{Cu}$ to Se stoichiometry, large grain size distributions, and grain size effects in the compound ${ }^{[26]}$.
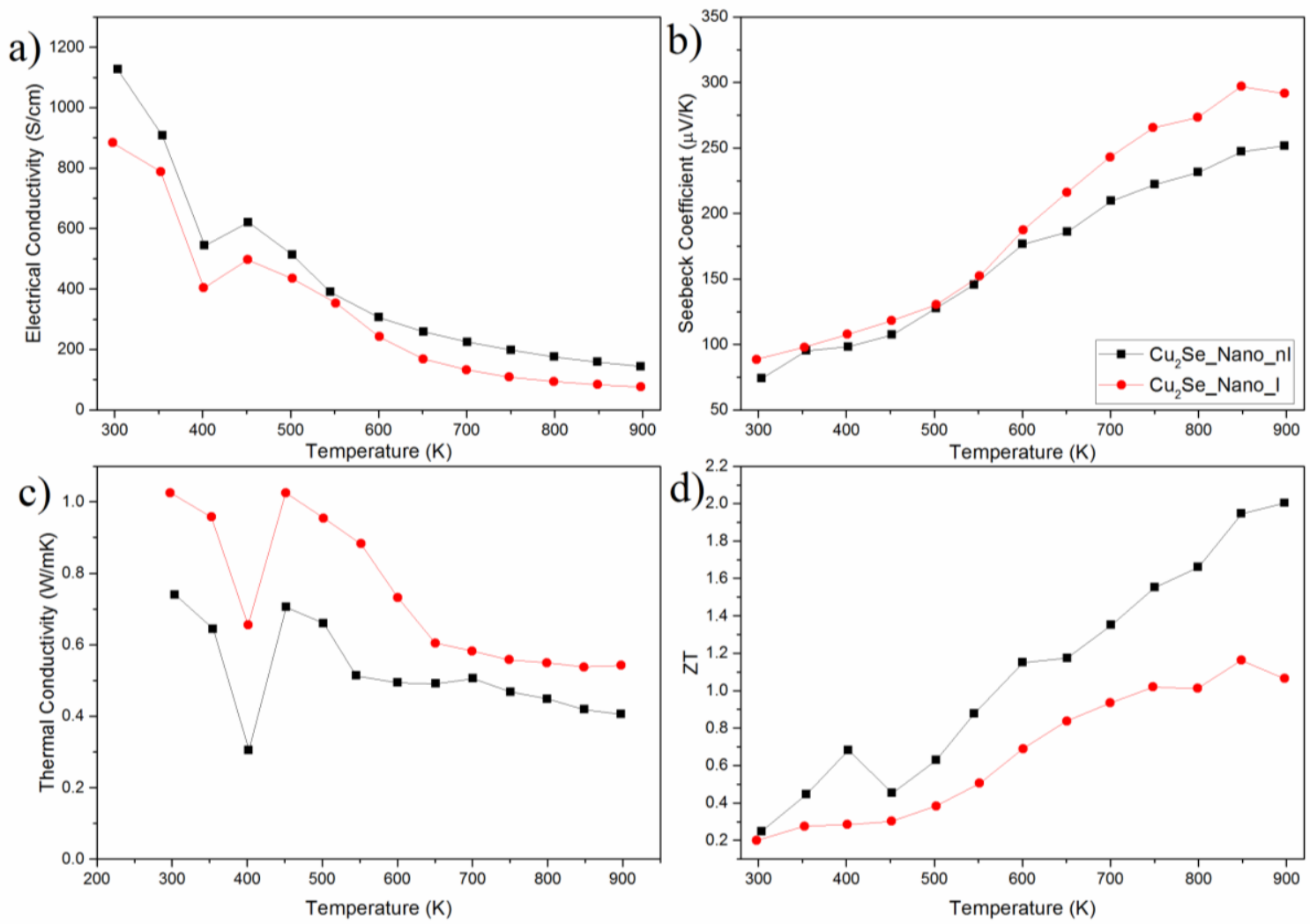

Figure 6: Thermoelectric transport data for the two samples measured between $300 \mathrm{~K}$ and 900 K: a) electrical conductivity, b) Seebeck coefficient, c) thermal conductivity, and d) estimated $Z T$ value.

The thermal conductivity values follow the same trend as reported in the literature, namely, the thermal conductivity of $\mathrm{Cu}_{2} \mathrm{Se}_{-}$Nano_1 starts at about $0.75 \mathrm{~W} / \mathrm{m}-\mathrm{K}$ at RT (Figure 6c), abruptly drops at the phase transition region and continues to decrease until it reaches a value of about $0.38 \mathrm{~W} / \mathrm{m}-\mathrm{K}$ at $900 \mathrm{~K}$. The reduced thermal conductivity value in our $\mathrm{Cu}_{2} \mathrm{Se}$ samples originates from the highly disordered structure due to randomly distributed $\mathrm{Cu}$ atoms in the structure ${ }^{[8,15}$, 27], as well as the phonon filtering effect due to different grain sizes, and grain boundary 
scattering present in the compacted pellet. We used the Wiedemann-Franz law to calculate the lattice contribution to the thermal conductivity of all samples by subtracting the electronic term ( $\boldsymbol{\kappa}_{e}=L_{0} \sigma T$ where $L_{0}, \sigma$ and $T$ are the Lorenz number, electrical conductivity and absolute temperature, respectively) from the total thermal conductivity. We assumed the system to be highly degenerate and the carrier scattering dominated by acoustic phonons. The Lorenz numbers for $\mathrm{Cu}_{2} \mathrm{Se}, 2.0 \times 10^{-8} \mathrm{~V}^{2} / \mathrm{K}^{2}$ for Cu2Se_Nano_1 and $1.8 \times 10^{-8} \mathrm{~V}^{2} / \mathrm{K}^{2}$ for $\mathrm{Cu}_{2} \mathrm{Se} \_\mathrm{Nano}$ nl were used from the literature ${ }^{[15]}$ to estimate the electronic part of the thermal conductivity.

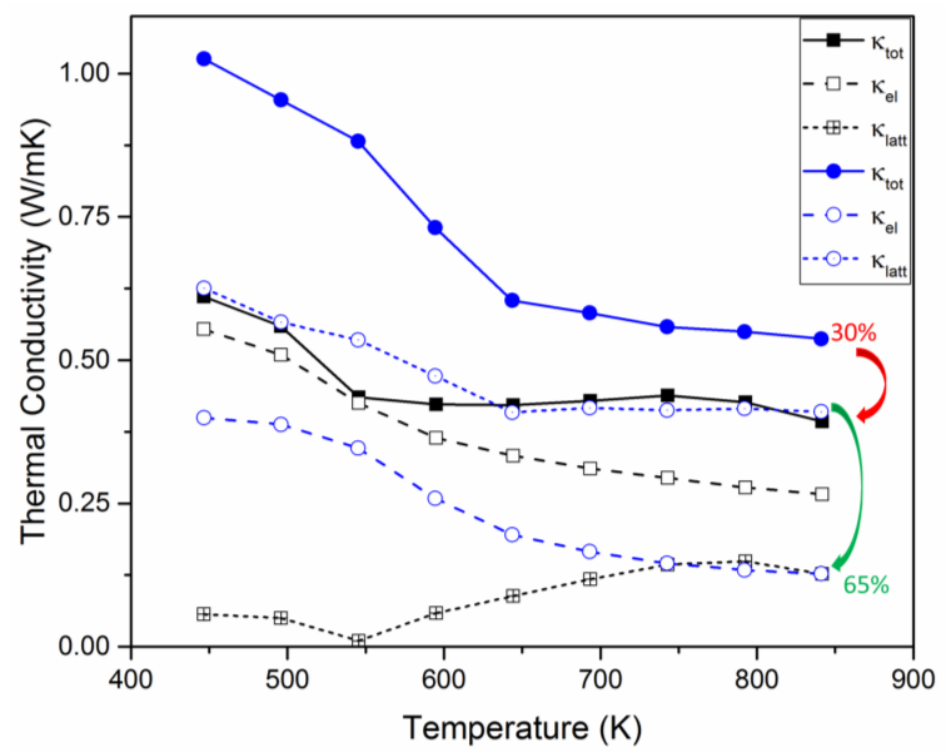

Figure 7: Thermal conductivity contributions in the two samples. The black lines (solid, dashed and dotted lines with square symbols) represent sample $\mathrm{Cu}_{2} \mathrm{Se}_{-}$Nano_l and the blue lines (solid, dashed and dotted with circle symbols) represent $\mathrm{Cu}_{2} \mathrm{Se} \_$Nano_nl

Looking at the thermal conductivity plot presented in Figure 7 as well as the initial thermal conductivity values illustrated in Table 2 , a clear $30 \%$ reduction in the total thermal conductivity is noticeable between the two samples at $850 \mathrm{~K}$. The estimated electronic part of the total thermal conductivity at room temperature for the sample $\mathrm{Cu}_{2} \mathrm{Se}_{-} \mathrm{Nano} \_\mathrm{nl}$ and for $\mathrm{Cu}_{2} \mathrm{Se} \_\mathrm{Nano} \_1$ reaches levels of $0.67 \mathrm{~W} / \mathrm{m}-\mathrm{K}$ and $0.47 \mathrm{~W} / \mathrm{m}-\mathrm{K}$, compared to the total thermal conductivity of 
$0.74 \mathrm{~W} / \mathrm{m}-\mathrm{K}$ and $1.02 \mathrm{~W} / \mathrm{m}-\mathrm{K}$, respectively. Moreover, the lattice thermal conductivity at the highest temperature of measurement $(900 \mathrm{~K})$ shows a $65 \%$ reduction at $850 \mathrm{~K}$, which is the result of the nanoengineered grains, causing enhanced phonon scattering, and filtering of low and high frequency phonons, both processes resulting in a reduced lattice contribution.

Table 2 Room temperature electrical conductivity, total thermal conductivity and electronic thermal conductivity of the two samples

\begin{tabular}{lccc}
\hline Sample Tag & $\begin{array}{c}\sigma \\
(\mathrm{S} / \mathrm{cm})\end{array}$ & $\begin{array}{c}\kappa_{\text {tot }} \\
(\mathrm{W} / \mathrm{m} \cdot \mathrm{K})\end{array}$ & $\begin{array}{c}\kappa_{\mathrm{el}} \\
(\mathrm{W} / \mathrm{m} \cdot \mathrm{K})\end{array}$ \\
\hline $\mathrm{Cu}_{2} \mathrm{Se} \_$Nano_nl & 1126 & 0.82 & 0.67 \\
\hline $\mathrm{Cu}_{2} \mathrm{Se} \_$Nano_1 & 884 & 1.02 & 0.47 \\
\hline
\end{tabular}

Any decrease in the size of the grains in a material results in an electrical conductivity reduction until the quantum confinement region is reached. There are more interfaces and grain boundaries in nanostructured materials in comparison to bulk samples. Electrons are scattered passing these interfaces and grain boundaries, resulting in suppressed electrical conductivity compared to their bulk counterparts ${ }^{[28]}$. However, recently it was shown that multiple scattering mechanisms in bulk samples enhance the Power Factor $(\mathrm{PF})$ of the material ${ }^{[29]}$. In other words, in nano/micro mix-grained composites, the dispersed nanoparticles are designed to preferably scatter phonons, while micro particles form a percolated network for electron transport ${ }^{[30]}$. Since small grain sizes cause confinement effects for lower energy charge carriers, the Seebeck coefficient also increases in nano/micro mix-grained composites. We believe a similar phenomenon is causing an enhancement in the Seebeck coefficient and electrical conductivity in our samples as compared to reported values in the literature. Figure $6 \mathrm{~d}$ represents the overall TE figure of merit $Z T$ of both samples prepared. High power factor and low thermal conductivity result in an exceptionally high TE figure of merit $Z T$ for $\mathrm{Cu}_{2} \mathrm{Se}$ _Nano_nl as compared to the 
highest reported $Z T$ values in Figure 8. Due to the methodology that preserved the nanostructure, $Z T$ values as high as 2 at $900 \mathrm{~K}$ were achieved for the nanostructured $\mathrm{Cu}_{2} \mathrm{Se}$, an almost $25 \%$ higher $Z T$ than the maximum value reported by Gahtori et al. ${ }^{[15]}$ at the same temperature.

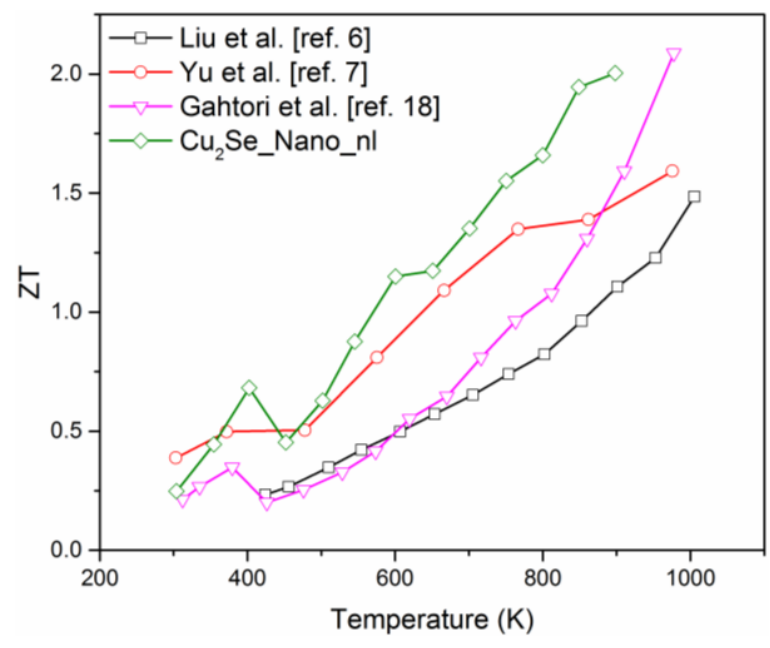

Figure 8: Comparison of $Z T$ values of $\mathrm{Cu}_{2} \mathrm{Se}$ samples prepared in this work with earlier reports The increase in ZT in our samples originates from the reduced thermal conductivity compared to other works (at least $10 \%$ reduction compared to the work of Gahtori et al. ${ }^{[15]}$ and more in comparison to others) as well as the higher Seebeck coefficient achieved with the optimized compaction process. The high $Z T$ at a lower temperature enables the usage of the material at temperatures lower than the material's instability region. According to the phase diagram of copper and selenium, slight variations in the value of $\mathrm{x}$ in the $\mathrm{Cu}_{2-\mathrm{x}} \mathrm{Se}$ create big issues on the material stability over $900 \mathrm{~K}^{[20]}$. This might result in migration of $\mathrm{Cu}$ ions and creating local stoichiometric variations resulting in local melting of those domains.

\section{Conclusions}

Using a highly reproducible and fully automated MW-assisted thermolysis route, copper selenide $\left(\mathrm{Cu}_{2} \mathrm{Se}\right)$ nanopowders were fabricated. Structural properties of the powder and the pellets compacted from the powder were investigated, and the transport properties of the 
resulting materials were determined. Optimized SPS compaction parameters were identified and used. The samples have a relatively high power factor and the thermal conductivity of the material is about $10-20 \%$ lower than the previously reported values in the literature. An exceptionally high ZT value of 2 was obtained at about $900 \mathrm{~K}$, one of the highest reported values in the literature. The MW-assisted synthesis method provides a promising route for a scalable fabrication of the nanostructured bulk thermoelectric $\mathrm{Cu}_{2} \mathrm{Se}$ material, which can be easily adopted by the industry for energy harvesting and other TEG applications. We concluded that using this preparation method with optimized compaction parameters, it is possible to enhance the $Z T$ value of nanostructured $\mathrm{Cu}_{2} \mathrm{Se}$ based compounds by $\sim 60 \%$ as compared to its bulk counterpart.

\section{Acknowledgements}

This work was supported by the Swedish Foundation for Strategic Research (SSF, Grant no EM11-0002) and Swedish Research Council (VR-SRL 2013-6780). Sedat Ballikaya acknowledges support by Scientific and Technological Research Council of Turkey (TUBITAK) with project number 115F510 and Scientific Research Projects Coordination Unit of Istanbul University (BAP) with project number of 21272. The work at the University of Michigan was supported by the Center for Solar and Thermal Energy Research, an Energy Frontier Research Center funded by the U.S. Department of Energy, Office of Basic Energy Sciences under the award DE-SC0000957.

\section{References}

[1] D. M. Rowe, Thermoelectrics Handbook: Macro to Nano, CRC Press, 2010.

[2] A. A. Sirusi, S. Ballikaya, C. Uher, J. H. Ross, Journal of Physical Chemistry C 2015, 119, 20293.

[3] H. H. Kou, Y. M. Jiang, J. J. Li, S. J. Yu, C. M. Wang, Journal of Materials Chemistry 2012, 22, 1950; M. C. Nguyen, J. H. Choi, X. Zhao, C. Z. Wang, Z. Zhang, K. M. Ho, Phys Rev Lett 2013, 111, 165502.

[4] C. M. Hessel, V. P. Pattani, M. Rasch, M. G. Panthani, B. Koo, J. W. Tunnell, B. A. Korgel, Nano Lett 2011, 11, 2560. 
[5] H. Liu, X. Shi, F. Xu, L. Zhang, W. Zhang, L. Chen, Q. Li, C. Uher, T. Day, G. J. Snyder, Nat Mater 2012, 11, 422.

[6] B. Yu, W. S. Liu, S. Chen, H. Wang, H. Z. Wang, G. Chen, Z. F. Ren, Nano Energy 2012, 1, 472.

[7] H. L. Liu, X. Shi, M. Kirkham, H. Wang, Q. Li, C. Uher, W. Q. Zhang, L. D. Chen, Materials Letters 2013, 93, 121; L. L. Zhao, X. L. Wang, J. Y. Wang, Z. X. Cheng, S. X. Dou, J. Wang, L. Q. Liu, Sci Rep 2015, 5, 7671.

[8] S. Ballikaya, H. Chi, J. R. Salvador, C. Uher, Journal of Materials Chemistry A 2013, 1, 12478 .

[9] D. Li, X. Y. Qin, Y. F. Liu, C. J. Song, L. Wang, J. Zhang, H. X. Xin, G. L. Guo, T. H. Zou, G. L. Sun, B. J. Ren, X. G. Zhu, RSC Advances 2014, 4, 8638.

[10] X. Su, F. Fu, Y. Yan, G. Zheng, T. Liang, Q. Zhang, X. Cheng, D. Yang, H. Chi, X. Tang, Q. Zhang, C. Uher, Nat Commun 2014, 5, 4908.

[11] R. D. Heyding, Canadian Journal of Chemistry 1966, 44, 1233.

[12] H. Kim, S. Ballikaya, H. Chi, J. P. Ahn, K. Ahn, C. Uher, M. Kaviany, Acta Materialia 2015, 86, 247.

[13] E. Filippo, D. Manno, A. Serra, Journal of Alloys and Compounds 2012, 538, 8; P. Lu, H. L. Liu, X. Yuan, F. F. Xu, X. Shi, K. P. Zhao, W. J. Qiu, W. Q. Zhang, L. D. Chen, Journal of Materials Chemistry A 2015, 3, 6901.

[14] K. Tyagi, B. Gahtori, S. Bathula, M. Jayasimhadri, N. K. Singh, S. Sharma, D. Haranath, A. K. Srivastava, A. Dhar, Journal of Physics and Chemistry of Solids 2015, 81, 100.

[15] B. Gahtori, S. Bathula, K. Tyagi, M. Jayasimhadri, A. K. Srivastava, S. Singh, R. C. Budhani, A. Dhar, Nano Energy 2015, 13, 36.

[16] V. M. Bhuse, P. P. Hankare, K. M. Garadkar, A. S. Khomane, Materials Chemistry and Physics 2003, 80, 82.

[17] P. Kumar, K. Singh, O. N. Srivastava, Journal of Crystal Growth 2010, 312, 2804; Y. Zhang, C. Hu, C. Zheng, Y. Xi, B. Wan, The Journal of Physical Chemistry C 2010, 114, 14849; X. Chen, Z. Li, J. Yang, Q. Sun, S. Dou, J Colloid Interface Sci 2015, 442, 140; X. Q. Chen, Z. Li, S. X. Dou, ACS Appl Mater Interfaces 2015, 7, 13295.

[18] L. W. Mi, Z. Li, W. H. Chen, Q. Ding, Y. F. Chen, Y. D. Zhang, S. S. Guo, H. M. Jia, W. W. He, Z. Zheng, Thin Solid Films 2013, 534, 22; Z. H. Han, Y. P. Li, H. Q. Zhao, S. H. Yu, X. L. Yin, Y. T. Qian, Materials Letters 2000, 44, 366; D. P. Li, Z. Zheng, Y. Lei, S. X. Ge, Y. D. Zhang, Y. G. Zhang, K. W. Wong, F. L. Yang, W. M. Lau, Crystengcomm 2010, 12, 1856; Y. F. Liu, J. H. Zeng, C. Li, J. B. Cao, Y. Y. Wang, Y. T. Qian, Materials Research Bulletin 2002, 37, 2509; H. L. Su, Y. Xie, Z. P. Qiao, Y. T. Qian, Materials Research Bulletin 2000, 35, 1129; L. Yang, Z. G. Chen, G. Han, M. Hong, Y. C. Zou, J. Zou, Nano Energy 2015, 16, 367.

[19] J. Choi, N. Kang, H. Y. Yang, H. J. Kim, S. U. Son, Chemistry of Materials 2010, 22, 3586; S. Deka, A. Genovese, Y. Zhang, K. Miszta, G. Bertoni, R. Krahne, C. Giannini, L. Manna, J Am Chem Soc 2010, 132, 8912; H. I. Hsiang, W. H. Hsu, L. H. Lu, Y. L. Chang, F. S. Yen, Materials Research Bulletin 2013, 48, 715.

[20] D. J. Chakrabarti, D. E. Laughlin, Bulletin of Alloy Phase Diagrams 1981, 2, 305.

[21] S. Bathula, M. Jayasimhadri, N. Singh, A. K. Srivastava, J. Pulikkotil, A. Dhar, R. C. Budhani, Applied Physics Letters 2012, 101, 213902; C. J. Vineis, A. Shakouri, A. Majumdar, M. G. Kanatzidis, Adv Mater 2010, 22, 3970.

[22] K. Wei, J. Martin, G. S. Nolas, Materials Letters 2014, 122, 289.

[23] C. R. Berry, Physical Review 1952, 88, 596. 
[24] H. J. Goldsmid, J. W. Sharp, Journal of Electronic Materials 1999, 28, 869.

[25] S. C. Riha, D. C. Johnson, A. L. Prieto, J Am Chem Soc 2011, 133, 1383.

[26] S. R. Gosavi, N. G. Deshpande, Y. G. Gudage, R. Sharma, Journal of Alloys and

Compounds 2008, 448, 344; C. V. Ramana, R. J. Smith, O. M. Hussain, physica status solidi (a) 2003, 199, R4; P. Jain, P. Arun, Thin Solid Films 2013, 548, 241.

[27] G. Chen, International Journal of Thermal Sciences 2000, 39, 471; W. Kim, J. Zide, A. Gossard, D. Klenov, S. Stemmer, A. Shakouri, A. Majumdar, Phys Rev Lett 2006, 96, 045901. [28] M. S. Dresselhaus, G. Chen, M. Y. Tang, R. G. Yang, H. Lee, D. Z. Wang, Z. F. Ren, J. P. Fleurial, P. Gogna, Advanced Materials 2007, 19, 1043.

[29] K. Biswas, J. He, I. D. Blum, C. I. Wu, T. P. Hogan, D. N. Seidman, V. P. Dravid, M. G. Kanatzidis, Nature 2012, 489, 414.

[30] A. Mehdizadeh Dehkordi, M. Zebarjadi, J. He, T. M. Tritt, Materials Science and Engineering: R: Reports 2015, 97, 1; J. P. Heremans, C. M. Thrush, D. T. Morelli, Physical Review B 2004, 70. 